\title{
Arquitecturas domésticas
}

\author{
Mapas heteropatriarcales del biopoder
}

\section{Domestic architectures}

Heteropatriarchal biopower maps

\section{María Laura Sarmiento}

Universidad Nacional de Córdoba-Argentina.; Centro de Investigaciones y estudiós sobre la Cultura y la Sociedad; Concejo Nacional de Investigaciones Científicas y Técnicas lauruch@hotmail.com 


\title{
Resumen
}

Este texto surge desde la imposibilidad de conversar con las mujeres del barrio. Mujeres compañeras con quienes comparto la vida hace más de diez años. Mujeres que nos conocemos en nuestras luchas existenciales por la tierra, por el trabajo, por la vivienda, por la autonomía, y que acuerpadas, sostuvimos diversas resistencias pero que jamás pudimos compartir la palabra "orgasmo".

Recorremos preguntas que van configurando un mapa de subjetividades presas de múltiples violencias, tanto territorializadas como encarnadas en personajes policiales, que nos ayudan a entender esta imposibilidad de conversación.

Con esta investigación desmantelamos la impunidad del disciplinamiento espacial doméstico, dejándolo en evidencia. Los resultados obtenidos son fundamento de nuestra actual línea de investigación de Arquitecturas Feministas, donde estamos revisando a la luz de la justicia erótica, el diseño patriarcal biopolítico y la casa como dispositivo.

Palabras clave: Arquitecturas feministas, Violencia territorial, Diseño patriarcal, Biopolítica, Bioética Urbana.

\begin{abstract}
This text come to light from the impossibility to talk with women in the field work. Female co workers with whom I share life more than ten years ago. Women who know each other in our existential struggles for the land, for work, for housing, for autonomy, and who agreed, we held various resistance but we could never share the word "orgasm."

We go through questions that configure a map of subjectivities imprisoned by multiple kind of violences, both territorialized and embodied in police characters, that help us understand this impossibility of conversation.

This research was revealing. It dismantled the impunity of domestic space that discipline our body and life, being the foundation of our current line of Feminist Architectural Research, where we are reviewing in the light of erotic justice, biopolitical patriarchal design and the house as a dispositive.
\end{abstract}

Key words: Feminist architectures, Territorial violence, Patriarchal design, Biopolitics, Urban Bioethics.

Para citar este artículo / To cite this article:

SARMIENTO, María Laura. Arquitecturas domésticas. Mapas heteropatriarcales del biopoder. En: [i2] Investigación e innovación en arquitectura y urbanismo [en línea]. Vol.8, no.1, junio 2020. ISSN: 2341-0515. 


\section{POR UN SILENCIO PERTURBADOR}

Tanto en el espacio social como en el corazón de cada hogar existe un único lugar de sexualidad reconocida, utilitaria y fecunda: la alcoba de los padres. Al resto sólo le queda esfumarse.

Michel Foucault, 1976

Hace más de diez años que trabajo metida a cuerpo entero en un barrio a las afuera de Córdoba, Argentina. La experiencia comenzó desde la militancia de una Arquitectura de a pie -con todos los ideales que puede tener una joven entusiasmada con la disciplina- y se fue transformando en lo que hoy es el fundamento de mi ser investigadora y científica. Lo que comenzó desde la técnica de planos y directivas legitimadas, mutó en creación de retóricas de valor para poder decir lo indecible. Cuando las palabras faltan, el cuerpo lo expresa. Y en esas latitudes los cuerpos gritan enmudecidos.

Este texto es una cartografía indisciplinada, que une puntos dispersos de nuestros mapas existenciales. Los de las mujeres del barrio, con sus dolores, pero también los nuestros, mujeres con el privilegio de poder dormir tranquilas. La vida doméstica nos hermana, al tiempo que nos distancia.

Las matrices de nuestra subjetividad son nuestras propias casas. El cuerpo-territorio que habitamos en lo cotidiano. Allí se dibujan las cartografias de nuestras diferencias, alianzas y potencias. Este texto explora esos mapas en cuatro claves:

1. Prisiones territoriales. ¿Dónde nuestra vitalidad es capturada? ¿Qué nombres tienen estas prisiones? Al parecer la trampa del poder biopolítico heteropatriarcal se aloja en el uso cotidiano de nuestros territorios vitales, tanto el tiempo -el largo plazocomo en el espacio. El efecto conseguido es la pérdida del extrañamiento frente al malestar y la incomodidad.

Lo macabro y estratégico, es su metodología. Utiliza la voluntad de una misma suponiendo que nos es posible una base común de libre albedrío- para embargar la propia vida, los sueños, etc. Se empeña y permuta la soberanía desde la misma vida soberana. De este modo la vitalidad queda presa en la forma material que toma la vida: territorios diseñados con estrategia, control y normalización.

2. Personajes policiales. ¿Quién encarna el patriarca de nuestra cotidianidad? ¿Cuál es el pacto de convivialidad con ese personaje? ¿qué está en juego? ¿Cuál es la pedagogía histórica de nuestro deseo?

Así, la deriva protagónica es la espacialidad y retórica funcional de nuestras casas: lo privado, lo íntimo, lo doméstico. Espacios condicionantes de nuestra potencia vincular. ¿Qué formas de vida y qué vínculos son permitidos en los espacios que habitamos? ¿Qué libertad vincular nos permitimos?

En el intento por responder estas preguntas, creamos la categoría de análisis de arquitecturas existenciales, que significan la materialidad-cuerpo-territorio resultante del cruce de lo vincular con lo espacial. Aparecen de este modo las agencias de nuestros espacios vitales íntimos, que lejos de ser nosotras mismas quienes los gestionamos, los operadores de dicha gestión resultan ser los personajes policiales. 
Éstos últimos, se encargan de la conservación y adiestramiento de tod ${ }^{*} \mathrm{~s} \mathbf{l}^{*} \mathrm{~s}$ habitant*s de la casa al orden heteropatriarcal: obedecer al macho dominante y cuidar a la familia.

Son estos mismos personajes policiales los dueños del poder, dueños del placer, expropiadores del deseo. Disponen y norman los usos de los espacios desde una presencia material difusa, pero policial vigilante omnipresente. Son los custodios de las prisiones domiciliarias y la obediencia debida.

3. Territorios vitales. ¿Cuáles son nuestros territorios vitales? ¿Dónde se sitúa nuestra lucha por la vida?¿Qué forma de vida arma nuestra vitalidad singular, y/o colectiva?

Por territorios vitales entendemos nuestra habitación del mundo y la forma que tienen nuestras vidas. Cuando las arquitecturas existenciales nos traen a la luz nuestro deseo capturado, nos damos con que el mismo ha sido colonizado, y nosotras hemos sido facilitadoras de dicha colonización. Es en este sentido que Carla Lonzi habla de mutilación cultural (Lonzi, 1976). Se nos ha profanado una parte de nuestra historia vital.

¿Quién pudiera seguir la deriva autónoma y explorar su propio deseo? ¿Cómo saber qué nos es propio y qué impuesto? Lo que nosotras proponemos es seguir la cartografía de nuestro cuerpo como brújula ética (Rolnik, 2018) trazada a partir de a quién y a qué le ponemos el cuerpo. Ese mapa nos conecta con nuestros territorios vitales, que en la mayoría de las mujeres con las que trabajamos y nos son cercanas, dibuja una historia de postergaciones en pos de la familia y $l^{*}$ s hij ${ }^{\star}$ s. Mujeres expropiadas de su propia dirigencia, y que les fue introducido un código ajeno: una desesperada necesidad de responsabilidad y cuidado de las crianzas. i¿Entonces?!

4. Justicia erótica. ¿Quién nos abrió el mundo de nuestra sexualidad? ¿Cómo la aprendimos? ¿Cuántas palabras tenemos para conocerla? ¿Qué formas posibles tiene? ¿Cómo nos hacemos un cuerpo-mujer-libre-deseante-sexuado?

¿Es posible una Justicia Erótica sin una política y una ética ejercida y aprendida, o al menos, habilitante?

Nuestro objetivo -distópico quizás- es desinstalar los modos de subjetivación heteropatriarcal que nos colonizan tanto la autonomía, como la Justicia Erótica. La apuesta para reivindicar la autonomía es corrernos del tutelaje y la obediencia debida, haciéndonos un cuerpo-territorio sintiente, conociente que nos arme y nos disponga alertas. Habilitar nuestro cuerpo doméstico cotidiano para poder desmarcarnos y ponerle nombre a nuestra complicidad con los personajes policiales que nos ordenan.

Respecto de la Justicia Erótica el desafío es hacer nacer personajes nuevos que se corran del dominio y las subjetivaciones heteropatriarcales. Poder experimentar nuestros territorios-cuerpo-casa y habitarles. Componerlos desde nuestros deseos vitales. 


\title{
2. PRISIONES TERRITORIALES
}

La cotidianidad de la vida va construyendo espacios donde nuestra vitalidad se va armando de formas, que estructuran nuestros modos de habitar y vincularnos con las personas: arquitecturas existenciales. Desde nuestro utopismo libertario nos encanta creer que es a partir de esta vitalidad que surge una creatividad fundamental, arquitecta de la casa de nuestro día a día.

Sin embargo, los hechos muestran que la metodología biopolítica de nuestra cotidianidad está mediada por múltiples dispositivos que capturan nuestra vitalidad singular y colectiva. De esta manera, en la inquietud por develar la forma en que estos dispositivos operan en el espacio de lo doméstico, significando éste no sólo lo estrictamente arquitectónico y funcional privado de la casa, sino también lo que es de uso común pero para una comunidad restringida, por ejemplo las cocinas, los espacios de espera de colegios, dispensarios, etc. Arquitecturas en las que se construye una territorialidad que le es singular y propia, y que en la mayoría de los casos, está vinculada a las tareas de cuidado y a la población femenina.

La trampa de estos dispositivos es la misma cotidianidad. Perdemos de vista el extrañamiento frente al malestar y la incomodidad. "Mal pero acostumbrada", son las palabras de una compañera que, consciente de su prisión, la acepta al no vislumbrar ninguna posibilidad de cambio. Ahora bien, ¿cómo llegamos a esto?

Desde la teoría en la Banalización de la Injusticia Social, dice Cristophe Dejours:

\begin{abstract}
“El sufrimiento suscita un movimiento de solidaridad y protesta sólo en caso que se establezca una asociación entre la percepción del sufrimiento del otro y la convicción de que dicho sufrimiento es causado por una injusticia. Por supuesto, sin percepción del sufrimiento del otro, no se podría plantear el problema de la movilización en la acción política y tampoco el de la justicia y la injusticia(...) Las personas capaces de disociar su percepción del sufrimiento del otro y el sentimiento de indignación que implicaría el reconocimiento de una injusticia suelen adoptar una postura de resignación. De este modo la denuncia funciona en un sentido poco habitual, según el cual su resultado sería familiarizar a la sociedad civil con la infelicidad e incluso constituir una preparación psicológica para soportarla." (Dejours, 2006)
\end{abstract}

Así entonces, va ocurriendo una prisión, al tiempo que se va construyendo el significado colectivo de la misma como acontecimiento invisibilizado. La comunidad restringida que lo habita, lo banaliza como un malestar "normal" y por ende, lo asimila y soporta sin protestas.

Otra cuestión fundamental a tener en cuenta para nombrar las prisiones es el devenir del tiempo a largo plazo. Justamente estos dispositivos del biopoder, nos instalan mediaciones para el armado de nuestra habitación en el tiempo. Y ese tiempo, es largo. Acompaña el mismo devenir de la vida.

Como arquitecta, he podido ser mitad cómplice, mitad dispositivo, mitad aprendiz de subversión de las prisiones, que yo misma fui testigo y hacedora en el transcurso de diez 
años, aproximadamente. Nótese con énfasis: advertir prisiones vitales, en un transcurso de diez años. ¿Quién pudiera anticiparse?

Con esto quiero hacer referencia a las mutaciones de la vida cotidiana, que son el resultado de una diversidad de elecciones, acciones, pensamientos, posibilidades. Cuestiones de distinta índole que van armando la estructura de nuestra forma-de-vida.

Así, el caso objeto de mi despertar crítico fue, esta misma comunidad de amigas que venían a morar a Argentina tras el sueño de una mejor calidad de futuro para sus hij ${ }^{\star}$ s. Originarias del Perú, materializaron su sueño al costo de su cotidianidad embargada.

Ese sueño, fue preso de una estafa del mercado informal de tierras. Así, compraron terrenos contaminados en un barrio a las afueras de la ciudad. Luego del transcurso de tres años, donde ya habían construido sus casas, comenzaron a ver que sus niñs y animales se enfermaban, que desde el suelo emergían jeringas y todo tipo de basuras. Pues les habían vendido un pedazo de basural a cielo abierto, no apto de habitación.

Cuando sus niñ*s comenzaron a enfermar, ése fue el acontecimiento que las llevó a acciones subversivas para salvar ese presente, su cotidianidad, sin ella ese futuro que soñaban no era posible.

Así tomaron una tierra, a la entrada de un barrio ciudad de Córdoba. Y fue allí, donde yo las conocí. Las acciones para salvar ese sueño fueron en todos los casos colectivas, sin embargo esta colectividad no implicaba la igualdad. Cada quien ocupaba roles distintos y todos necesarios por igual.

Entonces aquí comienza el devenir de la prisión que yo presencié. Ellas originarias del Perú, traían consigo la ética de la comunidad. Lo colectivo, la solidaridad y lo compartido, sin embargo, "el sueño" implicaba la casa propia, "el lugar para caerse muerto". Y es aquí mismo, donde las formas ya están predeterminadas. No hay elección posible. Ellas, querían la "argentinización", y esto implicaba ser parte de la ciudad, vivir a la manera de lo urbanizado aquí.

Y así fue como devino "la orden". Al principio, en el momento de la tierra tomada, la memoria viva de lo comunitario, era la ética que ordenaba sus vidas. La bioética urbana que les era propia. Ésta dibujaba en el territorio una disposición tal, que consistía en un círculo. Es decir, en una manzana cuadrada, de 100 metros por 100 metros, ellas habían organizado la implantación de sus casas de modo tal que armaban por un lado, una línea de control para lo extraño externo, disponiendo las entradas para afuera. Por otro, una zona de cuidado, disponiendo otro control para el centro. Para esa zona de cuidado operaba la miradas de quienes habitaban las cocinas de las casas, que estaban todas interconectadas. L*s niñ ${ }^{*}$ j jugaban en ese espacio, tod*s junt*s. Y las madres, las abuelas, las que no tenían hij ${ }^{*}$ s eran parte de un rol común. Es*s niñ ${ }^{*}$ s eran hij ${ }^{*}$ s de la comunidad.

Sin embargo, la orden del biopoder que establece cómo deben ser las formas-de-vida si quieren ser parte de la población que habita la ciudad, establece una serie de órdenes para la normalización, y consecuente ubicación en la interseccionalidad binaria del 
poder. Éstas órdenes son: división de lotes individuales, muro medianera, eliminación del corazón de manzana, prohibición de zonas comunes, obligación a plegarse a los servicios estatales brindados.

Cada una de éstas consignas del "ordenamiento territorial", implica una prisión territorial, colonial, neoliberal. La característica de territorial es fácil de percibir, sin embargo no hemos de olvidar que cada vida que habita un territorio, dibuja una territorialidad distinta, ligada a su vitalidad singular. De manera que, si esta parcela es determinada de antemano, la vitalidad que allí habite deberá ajustarse a esa norma territorializada. Es decir, la vitalidad queda presa de la forma material que tienen ese territorio diseñado con anticipación, con estrategia de control y normalización.

La característica de colonial deviene desde los orígenes, ya en 1680 la normalización de las Américas era llevada a cabo por "Las Leyes de Indias" -originalmente llamadas como Recopilación de leyes de los reinos de las indias-. Éstas son la legislación promulgada por los monarcas españoles para regular la vida social, política y económica de los territorios americanos y filipinos de ultramar de la Monarquía Hispánica. Las Leyes de Indias se constituían de nueve libros que trataban todos los asuntos de la vida y su ordenamiento. Así, éste biopoder que norma la vida cotidiana es una vieja herencia colonial que opera no solamente en la vida territorial, sino también en los asuntos del deseo y la sexualidad como veremos luego.

La prisión territorial-colonial-neoliberal queda constituída entonces a partir del despojo de la vitalidad colectiva de esa comunidad, que habitaba regida por una ética de solidaridad que cuida la vida, transmutada en individualismo, miedo y aislación. Hoy ese sueño de futuro para ${ }^{*}{ }^{*}$ niñ ${ }^{*}$ de las mujeres ha quedado más embargado que nunca. La cotidianidad ha sido transformada de modo tal, que todo lo que las fortalecía para ser más libres y autónomas de presente, ha sido transmutado en su antagónico radical.

Los cuidados que eran colectivizados, $1^{*}$ s niñ ${ }^{*}$ s de la comunidad quedaron en un pasado olvidado y silenciado. Éstos, derivaron en desconcierto, extrañamiento, competencia, y xenofobia. Las habladurías en negativo lo tomaron todo.

La aislación es la operación para el ordenamiento neoliberal de las vidas. El miedo, la construcción colectiva del momento. Cada quien aporta al mismo desde el fantasma que vive en su domesticidad individual y encerrada. Qué es ficción y qué realidad, no es posible diferenciar desde esa aislación, la consigna es dictada desde una tele-visión proyectada en infinitas versiones de pantallas. Desde allí la deriva pedagógica de qué imagen encarnar para soportar el malestar que nos afecta. Una imagen plana, sin sobresaltos, sin subversiones. Imágenes esclavas, cárceles de la vitalidad que anestesian y convierten en historia única nuestras miles maneras de crearnos un devenir. 


\section{PERSONAJES POLICIALES}

Relatamos en el apartado anterior, cómo desde el deseo - "un futuro para nuestr*s hij*s"- y los pactos necesarios para que ese deseo se abra paso en la realidad, se terminó tranzando con permisos habilitantes para que "la norma" determine y forme, desde el individualismo y la aislación, la manera de arquitecturar las vidas en lo cotidiano. De manera que la forma de vida libertaria y originaria que traían este grupo de mujeres consigo, quedó expropiada y prisionera de un biopoder hegemónico -clasista y racista-, urbano -colonial y territorial-, argentino -estatal y neoliberal.

Ahora achicamos la escala, tomaremos como foco de la mirada crítica las unidades habitacionales individuales. Nos situamos en las casas particulares, pero tenemos en nuestro marco de análisis histórico, el despojo acontecido.

De este modo, consideramos los espacios como condicionantes de nuestra potencia vincular. Analizaremos las formas de vida y los vínculos que se permiten o neutralizan, y que creamos en nuestras casas, a partir de los espacios que habitamos.

Para hablar de estas cuestiones fue necesario crear el concepto de arquitecturas existenciales, con éste tomamos en consideración tanto los territorios espaciales arquitectónicos per se, como los que se estructuran a partir de los vínculos corpo-territoriales. Cuando nos referimos a una casa, podemos entender que está armada a partir de, por ejemplo dos habitaciones, un baño, una cocina-comedor, un patio trasero, así como, por ejemplo, una madre, una hija, un padrastro, tres hijos. Pero entonces, nos quedan fuera de esa arquitectura de vida doméstica, la bioética que allí opera. Así es que con el concepto de arquitecturas existenciales, cruzamos lo vincular, con lo espacial, y desde allí, van apareciendo las distintas jerarquizaciones y binarismos con los que también el sistema patriarcal se agencia de nuestros espacios vitales íntimos.

Una característica común que tienen las casas de las compañeras del barrio, es que fueron arquitecturadas a partir de planos de barrios cerrados para una clase hegemónica. Los maridos de las compañeras, la mayoría trabajaban en la construcción. Así es que copiaron los planos y los materializaron en la construcción de sus propias casas, en el loteo informal de un barrio popular. Ahora bien, la estructura de las casas era de una vida doméstica estructurada a partir de un barrio creado a partir de la ficción de seguridad, del mostrarse, del orden disciplinar del diseño de autor. Así, apenas fueron construidas estas viviendas, tuvieron adaptaciones tipológicas desde la misma forma de vida que allí mismo habitaba.

En primer lugar, lo vital de estas vidas es la economía, así lo que eran espacios sociales estructurados como living-comedor, mutaron a espacios productivos con salida al exterior del tipo venta al público. Estos espacios productivos iban modificándose a medida que la casa se terminaba de construir, y era común a todas ellas. Éstos tenían las terminaciones de mayor factura. Es decir, de mayores recursos.

Respecto a la zona de servicios, baño y cocina. La cocina es el espacio vital de las casas. El más habitado, el que tiene cosas y se va modificando con el uso. El que oficia de 
reunión. El espacio recibidor. El baño, fue uno de los espacios que más tardó en aparecer dentro de las casas. Al principio, todas tenían excusado con letrina.

Lo que llamó mi atención es que cuando los baños comenzaron a construirse dentro de las casas, ninguno de ellos tenía un espejo. ¿Dónde se miraban su propia imagen los habitantes de estas casas? ¿En las habitaciones y dormitorios? O ¿será que los espejos se encarnan en las mismas personas que habitan las casas?

Como decíamos anteriormente, los planos originales tenían varias habitaciones, ya que eran casas de clase pudiente, la organización de los espacios estaba acondicionada a sus usos y costumbres. De manera que cuando hubo que reciclar el proyecto lo que más mutó fueron estos espacios. Pues sólo era posible una habitación para tod*s l*s habitantes de la casa. Entonces, he aquí la pregunta que nos trae a conversar ¿Cómo se hace el amor sin un espacio de intimidad? ¿Dónde ocurre el placer sin espacio? ¿Es necesario el espacio para la realización del placer?

Y así dimos con que los actos sexuales eran una práctica patriarcalizada. Y vuelvo nuevamente a la historia compartida. Los diez años de transitar por los territorios con las compañeras, y sus vidas singulares, sus existencias y tragedias cotidianas. Cuando llegué al barrio la mayoría de ellas tenía sólo un* o dos nin*s. Hoy la mayoría de ellas duplicó y hasta triplicaron esa cuenta. Ahora bien, cuando contaban el suceso de estar embarazadas, aparecían mandatos al estilo: "mi marido no quiere que ande más", y así, se apartaban de lo que quedaba de la práctica comunitaria de las reuniones y conversaciones de mujeres, “y no se metían más en líos”, quedaban "libres de las habladurías", quietitas, preñadas, encerradas, al cuidado de la reproducción familiar.

La otra versión de las prácticas sexuales era "bueno, cuando viene mi marido de trabajar, o de juntarse con los amigos tengo que estar lista", y ése "estarse lista" implicaba no sólo una preparación física, sino también alistar el deseo para recibirlo.

Y así es que dimos con que la casa era el panóptico de la gestión de la cotidianidad de las mujeres, no sólo por las violencias de la vigilancia enmudecida, sino porque los personajes policiales que queremos desmantelar, habitan y duermen con nosotras, en nuestras propias casas.

Personajes policiales, porque son los encargados de conservar y adiestrar a tod ${ }^{*}$ s ${ }^{*}$ s habitantes de la casa en el orden patriarcal. Pues tienen apropiado no sólo el placer sino también los cuidados. A partir de los usos de las prácticas sexuales, aparece clarísimo el binarismo jerarquizado del tutelaje. Quiénes son los dueños del poder en la categoría del placer sino ellos mismos. Ellos son los que disponen del cuándo, del cómo, del dónde, del con quién, y pareciera que también tienen ocupado el para qué, en una retroalimentación a ellos mismos. O bien, para agrandar la familia -que casi nunca es plan sino consecuencia- o bien, para descargar la libido -razón "normal" de una masculinidad patriarcal-.

La voz femenina no existe en los relatos, como sostiene Butler, lo que ocurre es una dependencia fundamental de un discurso que nunca escogemos, pero que, paradójicamente, inicia y sustenta nuestra acción. (Butler, 2007) 
Las pocas veces que nos dimos la posibilidad de conversar con las mujeres en relación a estos temas, el relato tiene la primera persona en un otro masculino. La propia voz salía en tono de chiste y por lo bajo. O sino, en la intimidad luego de alguna violación1.

De esta forma, volvemos a los personajes que sostienen en nosotras las relaciones patriarcales de poder. Será que trazamos nosotras mismas nuestra propia trampa. ¿Por qué elegimos compañer*s de vida que replican esas estructuras y capturan nuestra potencia vital? Y aquí hablo de potencia vital capturada porque justamente, pareciera que nos pasamos la vida trabajando para el placer de otr*s, ya sea marido, pareja, patrón, hij ${ }^{\star}$, etc.

Y somos introducidas en esto desde pequeñas.

Siguiendo con la genealogía de "El Orden" de la casa, las niñas de la comunidad son enseñadas a cuidar a sus hermanit*s desde pequeñas -desde los cinco o siete años ya les dejan al cuidado a ${ }^{*} \mathrm{~s}$ pequeñ ${ }^{*} \mathrm{~s}-\mathrm{y}$ a obedecer al Padre, sin explicaciones.

Obedecer y cuidar, son las consignas del patriarcado. Obedecer respecto de lo sexual. Cuidar respecto de la familia. Conforme a este orden, cuando ingresamos a una de estas viviendas patriarcales se percibe la presencia policial omnipresente. Ya sea el espacio productivo comunitario, ya sea la cocina, ya sea la habitación, cuando está "el hombre de la casa" es notable a partir de un cambio perceptible en la mujer.

Cuando conocemos en libertad a las compañeras de lucha, aguerridas en sus causas y convicciones, y sin embargo, cuando entramos a sus hogares con ellas, algo cambia. Como si estuvieran bajo una vigilancia invisible. Es otro territorio, de otra regencia. Cambian las libertades.

Opera en las casas una obediencia debida. Y nótese que esta obediencia no es cuestionada. Es de esas consignas normalizadas. Como si en juego estuviera la vida misma, pero ninguna participó de ese contrato. Y claro que no, Carole Pateman sostiene:

"El contrato social es una historia de libertad, el contrato sexual es una historia de sujeción. La dominación de los varones sobre las mujeres y el derecho de los varones a disfrutar de un libre acceso sexual a las mujeres es uno de sus puntos (...). La libertad de los varones y la sujeción de las mujeres se crea a través del contrato original, y el carácter de la libertad civil no se puede entender sin la mitad despreciada de la historia, la cual revela cómo el derecho patriarcal de los hombres sobre las mujeres se establece a partir de un pacto. La libertad civil no es universal; es un atributo masculino y depende del derecho patriarcal (...). El contrato es el medio a través del cual el patriarcado moderno se constituye". (Pateman, 1988)

Así es que al lado de las mismas compañeras, cambian su arquitecturas existenciales según estemos dentro o fuera de sus casas. Aunque todas son las "amas de la casa", hay

\footnotetext{
1 Hago un corte respecto del enunciado de violación, porque parece nombrado como cuestión cotidiana sin mayor incidencia, y es de ese modo. Más allá del registro de la violencia del día después, y del extrañamiento porque ese compañero llegó borracho o drogado, y no respetó las formas, no hay otro registro. Después se sigue la vida como si nada hubiera pasado. Y así ocurre en la memoria de todas. La violación por parte de la propia pareja es otra forma de práctica sexual normalizada.
} 
un amo y señor de ellas mismas. Entonces, cómo llegamos a ese episodio de prisión domiciliaria y obediencia debida.

\section{TERRITORIOS VITALES}

¿Cuál es la pedagogía histórica de nuestro deseo? Michel Foucault se preguntaba si la historia de la sexualidad debería leerse como la crónica de una represión creciente. Pues sostiene:

\footnotetext{
"Entonces la sexualidad es cuidadosamente encerrada. Se muda de lugar. La familia conyugal la confisca. Y la absorbe por entero en la seriedad de la función reproductora. En torno al sexo se establece el silencio. La pareja, legítima y procreadora, impone su ley. Se impone como modelo, hace valer la norma, detenta la verdad, retiene el derecho a hablar -reservándose el principio del secreto-. Tanto en el espacio social como en el corazón de cada hogar existe un único lugar de sexualidad reconocida, utilitaria y fecunda: la alcoba de los padres. Al resto sólo le queda esfumarse". (Foucault, 1976)
}

Será entonces que en ese esfumarse se ha autogestionado nuestro deseo, escondido, subyugado a un deseo patriarcal. Nuestro deseo ha sido colonizado y nosotras hemos sido voluntarias. Carla Lonzi, se preguntaba por la misma época, y lo expresa colectivamente en un manifiesto de la Rivolta Femminile:

“¿Y de qué han estado gozando los varones en la mujer, sino de una sexualidad sustitutiva que esta ha ido desarrollando a partir de la mutilación cultural de su propia sexualidad?(...)Al experimentar un placer que es mera respuesta al placer del varón, la mujer se pierde a sí misma como ser autónomo, exaltando la complementariedad del macho, y encontrando en él la motivación de su existencia. (...)El varón confía en el sentimiento de la mujer para que goce y no en el conocimiento que ella tenga de su sexualidad." (Lonzi, 1971)

De esta manera pareciera que nos debemos una página de autoconocimiento y construcción no solo de nuestra sexualidad sino de un deseo a la medida de nuestra vitalidad y ética de vida -bioética-. Frente a este desconcierto seguimos con el eje en nuestros territorios, esas arquitecturas existenciales que constituyen nuestra habitación del mundo y la forma que tienen nuestras vidas.

Así cuando nos preguntamos por nuestro territorios vitales, la diversidad es tal que no podríamos concluir en una fórmula que pudiera operar como norma. Por eso es que hablamos de libertad ética, a la manera de una rebelión o resistencia creativa en la que cada un* pueda seguir la deriva autónoma de exploración al deseo encarnado en su territorio cuerpo, y en los espacios que habitamos, revisando ese vínculo de a qué y a quién le ponemos el cuerpo según nuestras bioéticas.

Si repasamos la pregunta de a quién y a qué le ponemos el cuerpo, con las distintas respuestas dibujamos la cartografía de nuestros territorios vitales. Cuando hacemos las preguntas a nuestras compañeras del barrio, el nudo está en la familia, en l*s hij ${ }^{*}$. Ése es el espacio vital que más cuerpo nos ocupa, por lo que, cuando indagamos por la lucha por la vida en sentido amplio, todo apunta al mismo nucleo: "la lucha por vida digna, para educar a mis hijos", "la lucha es por un techo, para tener dónde cuidar a mis hijos", 
y si volvemos al principio de esta conversación, donde relatamos el origen de la movilización vital de las mujeres, lo que trazó el rumbo de su presente fue el futuro de l*s hij*s.

Y ante esta deriva de acciones y trabajos para otr*s, una historia de postergaciones propias, quedo silenciosa y pensando, porque también soy madre, soy madrastra y vengo de un linaje de mujeres madres, trabajadoras, que le han puesto el cuerpo a las balas cuando la cosa se puso fea -literalmente. Mujeres aguerridas, amantes de la vida y entregadas a su defensa, cueste lo que cueste. Y, sin embargo, mujeres expropiadas de su propia dirigencia. Siempre operó en ellas -cuando digo ellas vuelvo a hablar de las todas las mujeres que conozco y me son cercanas, transversalizo clase y generaciones- una obediencia a una autoridad masculina, ya sea, padre, marido, pareja, o bien, una desesperada necesidad de cumplimentar la responsabilidad de cuidado de las crianzas que históricamente les fue atribuida.

Cabe preguntarnos entonces, si nos es posible discernir territorios vitales propios, descentrados de esos territorios de obediencia y cuidado que el biopoder nos adjudicó, y que nos sigue capturando en esa trampa.

\section{JUSTICIA ERÓTICA}

Territorios vitales que nos sean auténticamente propios. Por aquí abrimos una escena completamente nueva, ya que nos aventuramos en un cambio de hecho, real, que acontece en la vida cotidiana, en el día a día de nuestra domesticidad vital. Así le abrimos una grieta a las matrices históricas más anquilosadas del patriarcado: sus modos de subjetivación.

Vamos a ensayar algunas pistas de transformación a partir de dos cuestiones que creemos radicales en sentido histórico, es decir, que son la raíz de nuestra liberación: autonomía y justicia erótica. Autonomía para corrernos del tutelaje y la obediencia debida. Justicia erótica para re-escribir nuestra historia, re-crear nuestra vincularidad con los cuidados, la sexualidad y la vida en su amplitud y profundidad toda. Como dice Suely Rolnik, poner nuestros cuerpos hacia la realización de nuestra pulsión vital para que pueda cumplir su destino ético.

Entonces, respecto de nuestra autonomía, necesitamos hacernos de un cuerpo. Necesitamos convocar el deseo para crear algo que logre dar forma y materializar lo que la vida nos pide cuando está amenazada para recobrar el equilibrio. En palabras de Suely:

"La resistencia hoy consiste en reconectar lo más posible con nuestra condición de viviente, activar nuestro saber-de-viviente, saber-del-cuerpo, y que este saber es nuestra brújula. Pero una brújula ética, porque su norte (o más bien, su sur) no tiene imagen, ni gestos, ni palabras.

(...)Se tiene que transfigurar las formas sociales y transvalorar sus valores cada vez que la vida nos indica que ya no se puede seguir así, porque la sofoca. Y esto va desde la cosa más macropolítica hasta nuestra sexualidad.

(...)Cuando la vida se encuentra amenazada, cuando el río siente los efectos de esas fuerzas destructivas en su vitalidad, inmediatamente inventa su manera de seguir, bajo otra forma, transfigurándose, creando otro lugar, de otra manera; el río cumple así el destino de la vida, que en su esencia es un proceso continuo de transfiguración para seguir perseverando". (Rolnik, 2018) 
Autonomía entonces implicaría, territorializar nuestra vida, hacernos de un cuerpo sentido, vivido, sabido, habitado. Sólo así podremos crearnos una vida a nuestra medida. Ésta territorialidad defiende nuestra autonomía. Al sensibilizar nuestro proceso de subjetivación nos pone en alerta de las múltiples violencias extractivistas de nuestra vitalidad, nuestro deseo y nuestro erotismo.

Así la invitación de autonomía, para fortalecerla, es habitar nuestro cuerpo doméstico, cotidiano, las arquitecturas existenciales de nuestro día a día y conocer cada vez más, cuál es nuestro personaje en la escena machista patriarcal para poder intervenirla y desmontar esa fuerza micropolítica. La escena patriarcal no sólo está hecha por personajes varones. Lo que conversamos en párrafos anteriores da cuenta de toda la complicidad y funcionalidad femenina. De esta manera, para que pueda ser posible alguna justicia erótica, necesitamos en primer lugar autonomía. Insurrecciones y resistencias creativas, que hagan nacer personajes nuevos que se corran del dominio y de las subjetivaciones patriarcales. Experimentemos nuestros territorios-cuerpos-casa y habitemos abriéndole paso a nuestros deseos vitales.

\begin{abstract}
"A medida que lo vamos haciendo (porque es una lucha de toda la vida), el otro personaje, el macho en este caso, no tiene más con quien hablar en aquella escena teatral. Entonces existen dos posibilidades: o bien tendrá la fuerza, él también de empezar a inventar otro personaje, otros personajes, mil personajes, a partir de los afectos que está viviendo en cada momento, o bien va quedar atrapado en una fantasía de que afuera de esa escena y de su personaje en ella no hay nada, es el colapso de sí mismo y de su mundo." (Rolnik, 2018)
\end{abstract}

De esta manera, desde este corrimiento de sostenedoras de las relaciones de poder patriarcales se nos abren mundos nuevos. Una micropolítica cuya meta es la creación de otras formas de vivir donde la justicia erótica sea posible.

Ahora bien, cómo serían las acciones para dar lugar a justicia erótica alguna. Lo vital es relacional. Importa la experimentación compartida del cuerpo que se ha hecho, para que los conocimientos del mismo sean solidarios en la resistencia contra la subjetivación patriarcal. Lo relacional hace justicia en la sola existencia territorializada. Vincularidad y erotismo nos acercan cada vez más hacia una ética del deseo, y éste como tal, a una justicia erótica.

Sin embargo, nos queda recorrer el mapa histórico de nuestra sexualidad para encarnar libremente un erotismo que le dispute la operación subjetiva al régimen patriarcal. ¿Quién nos abrió el mundo de nuestra sexualidad? ¿Cómo la aprendimos? ¿Cuántas palabras tenemos para conocerla? ¿Qué formas posibles tiene? ¿Es para tods igual? ¿Qué intersección se cruza en esta cuestión vital? ¿Cómo nos hacemos un cuerpomujer-libre-deseante-sexuado?

Comencemos entonces, quién nos abrió el mundo de nuestra sexualidad. A partir del relato de los párrafos anteriores, tenemos conocimiento que la sexualidad femenina está colonizada, y se garantiza esta forma encorsetada y autoritaria, a partir del control de los modos de subjetivación patriarcales. Desde pequeñas se nos enseña a las mujeres, la sexualidad como problema, ya sea como peligro, como secreto, como tabú, como 
algo de la índole de lo sagrado, con el mandato de atesorarlo para "aquel" que sea digno. De entrada, se nos expropia nuestra autodeterminación en el devenir sexual. Y eso es lo problemático, porque se nos expropia la posibilidad exploratoria sensual y deseante, y se inmortaliza una moralidad sexual oprimida, a la dialéctica del amo patriarcal. La sexualidad femenina es enseñada como el problema de lo reproductivo, lo gestacional, y claramente, eso es problema sólo de quienes tienen útero, no de quien detenta la cultura del pene. Así, el patriarcado mantiene inalterables los términos de su dominio (Lonzi, 1971:75).

Las jóvenes se inauguran en sus devenires sexuales, expropiadas de una sexualidad placentera y sabida. De manera que se habitúan inconscientemente a una falta de placer e imponiéndose la presencia masculina para satisfacer las necesidades ligadas a la mitificación del mismo, pero no ligadas al erotismo. De este modo, se nos enseña el modelo de sometimiento, pero no el conocimiento de nuestro sexo.

Por esto es vital recuperar las etapas del conocimiento subjetivo del placer de las niñas, las jóvenes, partiendo de la experiencia autoerótica: esta es la educación sexual que en este momento tiene un nexo con sensaciones y emociones que nos son propias (Lonzi, 1971: 122).

Cuando hicimos la experiencia en el barrio con las mujeres y propusimos un tallercito de sexualidad, porque las madres estaban preocupadas por sus hijas jóvenes que ya comenzaban a ausentarse algunas noches con sus novios, y comenzamos sí, con la biología de la mujer.

El tallercito de sexualidad propició una compartición de índole personal, donde cada una compartió su experiencia de cuando "le vino", sus experiencias de menstruación. Lo sorprendente fue que para todas fue una sorpresa, algunas aterrorizadas, porque pensaban que se estaban por morir, que se habían lastimado, y las mil asociaciones posibles para una sangre inesperada.

Ese instante, la llegada de la sangre es lo que habilitaba la palabra. La autorización para hablar de ello bajo el tutelaje de alguna otra mujer, y por supuesto, con el pacto de lo ultra secreto.

Como investigadora militante no puedo no hacer la mirada de mi propia subjetivación como mujer "inaugurada" a la femineidad. En mi caso no fue la sangre lo que habilitó las palabras, pero sí, la cuestión etaria, quizás mi curiosidad, y las preguntas que le hacía a mi mamá. Hasta hoy recuerdo las lecciones de sexualidad, sentada debajo de una enredadera de jazmines.

Así, en esta comparativa de clase y orígenes, la diferencia es lo que habilitó las palabras, pero las lecciones y el conocimiento que dio lugar a la subjetivación femenina fue, en ambos casos, la relatividad a lo reproductivo. Y volvemos nuevamente al nudo autoritario por excelencia: la conservación de la familia.

Y qué sucede entonces con esas formas de sexualidad "ilegítima" las que no se reglan en lo reproductivo. Acaso queda por fuera de la norma y su regulación. Pues no. Pareciera 
que lo que se sale de la protección de la familia queda a librado a la regulación de la ganancia. Esas otras sexualidades no gestantes fueron capturadas por la ganancia. El burdel o el manicomio eran los lugares de tolerancia posibles. Y las que escaparon de esas capturas se han mantenido hasta hace poco en la clandestinidad, con lenguajes circunscriptos y cifrados.

Y allí se abre toda una política erótica donde los distintos grados de conocimiento y libertad en relación a la sexualidad, determinan eroticidades diferentes, que dan forma a su vez, políticas diferenciales en cada caso. Enrique Dussel habla de una tríada eróticapedagógica-política y cómo cada una de las partes se determinan mutuamente.

Es claro, que, a partir de la política patriarcal neoliberal, toda pedagógica está condicionada por una sexualidad masculina dominante, cercenando cualquier erótica y, por lo tanto, toda ética del deseo posible. Ocurre de este modo una opresión erótica que va en la misma línea de la desigualdad social.

La interseccionalidad feminista -clase, raza, género, edad, geografía, etc.- propone una lectura en clave política que nos permite abrir nudos para repensarnos, y para mirar críticamente lo que se nos da, no sólo como norma sino como "natural". "La perspectiva reproductiva de la mujer es natural”. Y bajo esa consigna nos quedan expropiados todas las posibilidades eróticas.

Nos aprisiona entonces una política sexual. Donde el dispositivo de la sexualidad, se monta no tanto sobre la represión del sexo, sino sobre su reglamentación, conocimiento y control (Donda, 2005). De manera que, si pensamos en la política y su interseccionalidad, lo mismo ocurre con la erótica. La opresión y su desigualdad son consecuencias de una política erótica, establecida a partir de sus mecanismos de control y tecnologías de poder aplicadas sobre la sexualidad.

Nuestra propuesta habita en la iniciación creativa de una política erótica libertaria en clave feminista, donde la base para el conocimiento sea la libertad autoexploratoria y su compartición. El encuentro de los cuerpos y su posibilidad lúdica, donde cada parte sea respetada en autonomía e integridad, de manera que ningún cuerpo quede subyugado a rendirle culto a otro, por motivo ninguno. Y lo relacional vincular como medida para una ética deseante que habilite, desde la realidad cotidiana de cada cuerpo y cada habitación, su justicia erótica.

\section{CONCLUCIONES}

La intención de este apartado no es de ninguna manera cerrar, sino hacer un punteo de cuestiones que nos parecen claves para seguir abriendo, profundizando, seguir explorando con una lupa feminista y situada en la justicia erótica. Así pues, consideramos fundamental:

Estar atentas al malestar y la incomodidad que expresan nuestros cuerpos-territorios, pues en la puesta en valor de nuestro malestar y notarlo, marcarlo, será posible un mapa que irá poniéndole nombre a nuestras prisiones territoriales. Encierros que, de momento, gozan de nuestro consentimiento mudo. El patriarcado neutraliza las estrate- 
gias de libertad que nos damos las mujeres, fundamentalmente las comunitarias. Su operación biopolítica consiste en aislar e individualizar las responsabilidades, como, por ejemplo, los cuidados. De este modo, nos urge re-flexionar. Producir un movimiento en la imagen que encarnamos para soportar el malestar que nos afecta, y cortar con la complacencia que sostiene la complicidad.

La pregunta fundamental para estar alertas desde nuestra sensibilidad es ¿quien encarna en patriarca de nuestra cotidianidad? Muchas veces -la mayoría- somos nosotras mismas que nos hemos tragado "la orden". Sin embargo, es menester desmantelar esos personajes policiales que condicionan nuestros espacios existenciales, así como nuestra potencia vincular. Estos personajes quizás salten a la luz tras preguntarnos por el placer y el ocio: ¿Cuáles son los espacios donde nos propiciamos placer? ¿Cuáles son esos tiempos nuestros? ¿Quién o qué nos lo limita? Y así, construirnos ese mapa para saber(nos), que nos permita(mos) el movimiento, la no complacencia y sí, la autocomplacencia tan universalmente defenestrada.

Así, con la construcción de estos mapas, volver al gobierno de nuestros territorios vitales. Y que la práctica aprendida de nuestro deseo, que hasta ahora ha sido un continuum esfumarse de nuestra propia gestión, situarla en el centro de nuestra ética y política cotidiana.

Nuestra domesticidad vital dependerá de la medida de libertad en que sea posible recomponer la matriz base de nuestra subjetivación, a partir del encuentro de los cuerpos y su experimentación lúdica, en igualdad de respeto e integridad, es decir, de la puesta en vigencia de una justicia erótica.

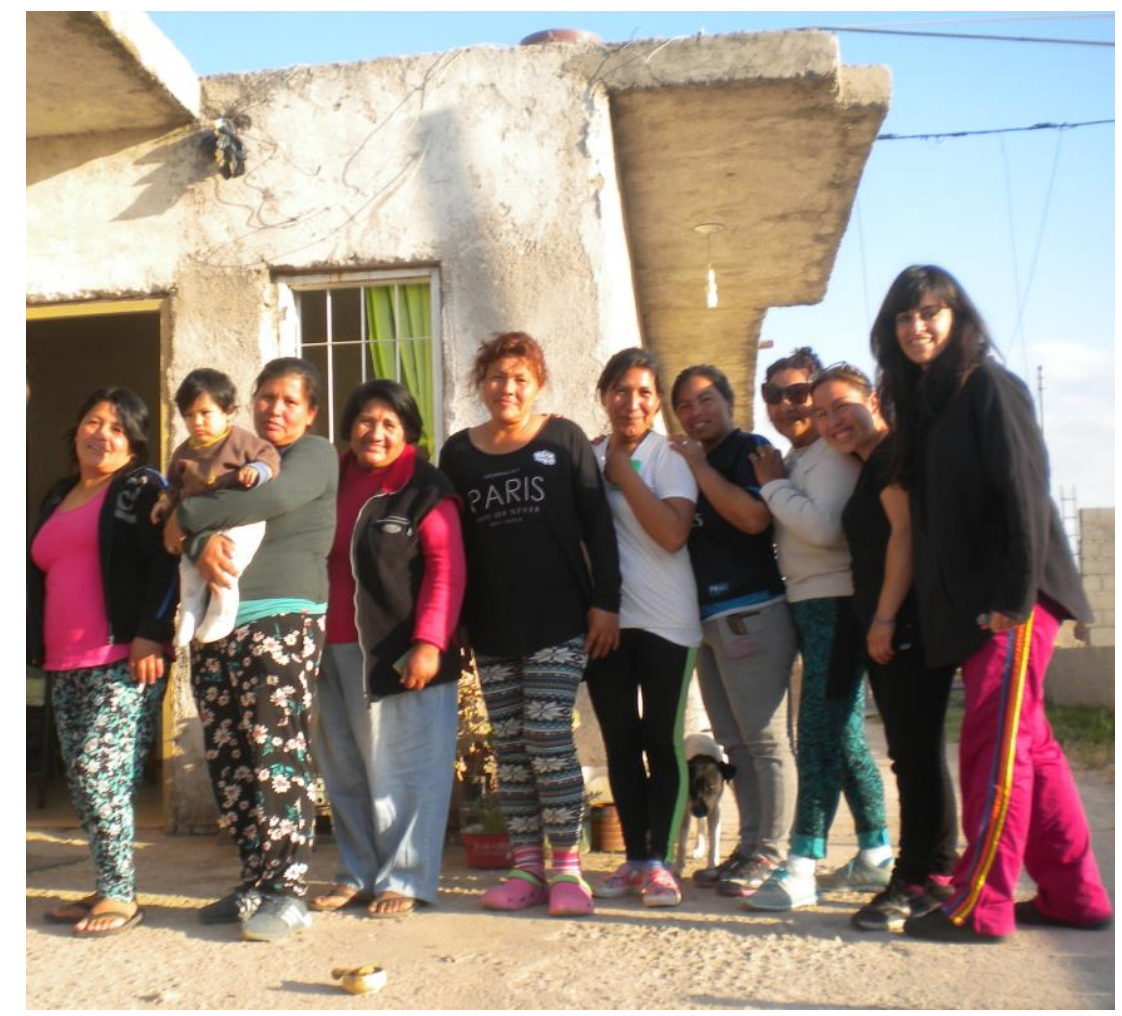




\section{BIBLIOGRAFÍA}

AGAMBEN, G. Homo sacer: el poder soberano y la nuda vida. 1a ed. Valencia, España.

Pre-Textos, 1998. ISBN: : 9788481912067

ARENDT, H. Los orígenes del totalitarismo.1a ed. Madrid. Ed. Alianza, 2017. ISBN: 9788420647715

ARENDT, H. Sobre la Violencia. 1a ed. Buenos Aires. Ed. Alianza, 2015. ISBN: 9788491811114

BUTLER, J. El género en disputa. El feminismo y la subversión de la identidad. 1a ed. Buenos Aires. Ed. Paidós, 2007. ISBN: 978-84-493-2030-9

CRENSHAW, K.1989. Demarginalizing the Intersection of Race and Sex: A Black Feminist Critique of Antidiscrimination Doctrine, Feminist Theory and Antiracist Politics, University of Chicago Legal Forum: Vol. 1, Article 8. ISSN: 0892-5593. Disponible en: http://chicagounbound.uchicago.edu/uclf/vol1989/iss1/8

DEJOURS, C. La banalización de la injusticia social. 1a ed. Bs As. Topia, 2006. ISBN:9871185103

Donda, C. Lecciones sobre MICHEL FOUCAULT Saber, sujeto, institución y poder político. 1a ed. Córdoba. Colección Conjetura de Filosofía.. Editorial Universitas, 2005. ISBN:9879406508

DUSSEL, E. Para una erótica latinoamericana. 1a ed.Venezuela. Imprenta del Ministerio para el Poder Popular de la Cultura, 2007. ISBN: 9789803966669

FOUCAULT, M. La arqueología del saber. 1a ed. Buenos Aires. Argentina. Siglo XXI, 1967. ISBN:987110507X

FOUCAULT, M. Saber y verdad. 1a ed. Madrid. España. Ed, La piqueta, 1985. ISBN: 8474430380

FOUCAULT, M. El coraje de la verdad. 1a ed. Buenos Aires. Argentina. Fondo de la cultura económica, 2011. ISBN: 9789505578535

FOUCAULT, M. Vigilar y castigar. El nacimiento de la prisión. 1a ed. Buenos Aires. Argentina. Siglo XXI, 2012. ISBN:987-98701-4-X

FOUCAULT, M. Sexualidad y política. Escritos y entrevistas 1978-1984. 1a ed. Buenos Aires. El cuenco de Plata, 2016. ISBN: 9789873743702

FOUCAULT, M. Historia de la Sexualidad. La voluntad de saber. 2a ed. Buenos Aires. Siglo XXI Editores, 2018. ISBN: 9789876290388

GAGO, V.; Gutierrez, R.; el all.. 8M. Constelación feminista. 1a ed .Bs As. Tinta Limón, 2018. ISBN: 9789873687372

GUATTARI, F. y ROLNIK, S. Micropolítica: Cartografías del deseo.1a ed . Bs As.Tinta Limón, 2013. ISBN:9789872739027

KIRKWOOD, J. (1983) Feminismo como negación del autoritarismo. Material de discusión programa Flacso-Santiago de Chile. Número 52. Disponible en: http://flacsochile.org/biblioteca/pub/memoria/1983/001058.pdf

LAZZARATO, M. Políticas del acontecimiento. 1a ed .Buenos Aires. Tinta Limón, 2006. ISBN:9872168989

LONZI, C. Escupamos sobre Hegel y otros escritos. 1a ed . Bs As. Tinta Limón, 2017. ISBN:9789873687310

PATEMAN, C. El contrato sexual. 1a ed. Barcelona. Anthropos, 1995. ISBN: 84-7658-462-8

ROLNIK, S. Esferas da Insurreicao. Notas para uma vida nao cafetinada.1a. ed. Brasil. N-1 Edicoes, 2018. ISBN: 9788566943597

SARMIENTO, M. L. Bioètica Urbana. Una herramienta biopolìtica frente los abusos de expropiación de la vitalidad colectiva corpo-territorial. En Sarmiento, M. L. y Araujo de Assumpção, E. (comp). Bioética urbana desde el Sur global : territorialidades bioéticas emergentes-1a ed . - Ciudad Autónoma de Buenos 
Aires : CONICET - Consejo Nacional de Investigaciones Científicas y Técnicas, 2019. ISBN: 9789506921583

SARMIENTO, M. L. Epistemologìas vivas. Poner el cuerpo frente al despojo racional del mandato heteropatriarcal. En Bard Wigdor, G y Bonavitta, P. (comp). Feminismos Latinoamericanos: recorridos, acciones, epistemologìas. 1a ed . - Ciudad Autónoma de Buenos Aires : CONICET - Consejo Nacional de Investigaciones Científicas y Técnicas, 2017. ISBN: 9789506921392

SEGATO, R. L. La crítica a la colonialidad en ocho ensayos. Y una antropología por demanda.1a. ed. Buenos Aires. Ed. Prometeo Libros, 2013. ISBN: 9789875746251

SEGATO, R. L. La escritura en el cuerpo de las mujeres asesinadas en Ciudad Juárez. 1a. ed. Buenos Aires. Tinta Limón, 2013. ISBN: 9789872518578

SEGATO, R. L. La guerra contra las mujeres. 1a. ed. Madrid. Traficantes de Sueños, 2016. ISBN:9788494597855

\section{Bio}

María Laura Sarmiento. Arquitecta. Doctora en Arquitectura. Doctoranda en Estudios de Género. Especialista en Bioética Urbana. Investigadora del Concejo Nacional de Investigaciones Científicas y Técnicas. Temática de investigación: Bioética Urbana; Conflictos Urbanos; Gestión Feminista del HábitatUrbanismo Feminista.

https://arquitecturasfeministas.home.blog/

https://bioeticaurbana.wordpress.com/

María Laura Sarmiento. Architect. PhD in Architecture. PhD in Gender Studies. Urban Bioethics Specialist. Researcher of the National Council of Scientific and Technical Research. Research theme: Urban Bioethics; Urban Conflicts; Feminist Management of Habitat-Feminist Urbanism

https://arquitecturasfeministas.home.blog/

https://bioeticaurbana.wordpress.com/ 